\title{
Conciliando agência e contexto na dinâmica da mudança institucional
}

\author{
Reconciling agency and context in the dynamics of institutional change \\ Diego Maganhotto Coraiola ${ }^{1}$ \\ Universidade Positivo / Programa de Mestrado em Administração, Curitiba - PR, Brasil \\ Márcio Jacometti ${ }^{2}$ \\ Universidade Tecnológica Federal do Paraná / Departamento Acadêmico de Ciências Humanas e Sociais Aplicadas, Cornélio \\ Procópio - PR, Brasil \\ Marystela Assis Baratter ${ }^{3}$ \\ Fundação Getulio Vargas / Instituto Superior de Administração e Economia do Mercosul, Curitiba - PR, Brasil \\ Sandro Aparecido Gonçalves ${ }^{4}$ \\ Universidade Federal do Paraná / DAGA - Departamento de Administração Geral Aplicada, Curitiba - PR, Brasil
}

\section{Resumo}

Este ensaio apresenta estrutura analítica que busca conciliar elementos da agência e do contexto na análise de processos de mudança institucional. A estrutura está baseada na articulação entre as abordagens do institutional work e da mudança institucional gradual. Ambas as abordagens foram criadas como alternativas a perspectivas que enfatizavam demasiadamente elementos estruturais (como a path dependence theory) ou a ação (como o empreendedorismo institucional). No entanto, apesar dos ganhos analíticos que ambas trouxeram para o estudo da mudança institucional, ainda mantêm fortes vínculos com os pressupostos das tradições de pesquisa das quais emergiram. Uma aproximação entre tais esquemas teóricos permite maior rigor para investigar processos de mudança institucional e possibilita aos pesquisadores maior consciência sobre os pressupostos inerentes a cada perspectiva, assim como incentiva a busca por abordagens que encadeiem elementos capazes de prover explicação adequada para a manutenção e a mudança institucionais. No centro dessa proposta, encontra-se a busca por entender a dinâmica da vida institucional. O contexto institucional possui certo nível de plasticidade e pode ser modificado de acordo com a disponibilidade de práticas, significados e recursos. A efetivação desse potencial de mudança está relacionada à capacidade dos atores, seus níveis de reflexividade institucional e munificência de recursos. As práticas de criação, manutenção e dirupção das instituições em determinado contexto serão, portanto, resultado da interação entre as características do contexto institucional (nível de plasticidade institucional) e dos tipos de atores sociais (nível de discricionariedade institucional).

Palavras-chave: Trabalho institucional. Mudança institucional gradual. Agência. Reflexividade. Contexto institucional.

Artigo submetido em 27 de maio de 2013 e aceito para publicação em 2 de fevereiro de 2015.

\section{DOI: http://dx.doi.org/10.1590/1679-39518879}

${ }^{1}$ Doutor em Administração pela Universidade Federal do Paraná (UFPR); Professor do Programa de Mestrado em Administração da Universidade Positivo. Endereço: Rua Professor Pedro Viriato Parigot de Souza, 5300, Cidade Industrial, CEP 81280-330, Curitiba PR, Brasil. E-mail: dcoraiola@gmail.com

${ }^{2}$ Doutor em Administração pela Universidade Federal do Paraná (UFPR); Professor e Chefe do Departamento Acadêmico de Ciências Humanas e Sociais Aplicadas da Universidade Tecnológica Federal do Paraná (UTFPR), Campus Cornélio Procópio. Endereço: Av. Alberto Carazzai, 1640, Centro, CEP 86350-000, Cornélio Procópio - PR, Brasil. E-mail: jacometti@utfpr.edu.br

${ }^{3}$ Doutora em Administração pela Universidade Federal do Paraná (UFPR); Professora do Instituto Superior de Administração e Economia do Mercosul (ISAE/FGV). Endereço: Av. Visconde de Guarapuava, 2943, Centro, CEP 80010-100, Curitiba - PR, Brasil. Email: marystela.baratter@gmail.com

${ }^{4}$ Doutor em Administração pela Fundação Getulio Vargas/EAESP; Professor Adjunto do DAGA - Departamento de Administração Geral Aplicada da Universidade Federal do Paraná (UFPR). Endereço: Av. Pref. Lothário Meissner, $632-2^{\circ}$ andar - Jardim Botânico, CEP 80210-170, Curitiba - PR, Brasil. E-mail: sag2@uol.com.br 


\begin{abstract}
This essay introduce an analytical structure that seeks reconciling elements of agency and context in the analysis of institutional change dynamics. The framework is based on the interconnection between the institutional work and gradual institutional change approaches. Both were created as alternatives to theoretical perspectives that put too much emphasis on social structure (e.g. path dependence theory) or to human agency (e.g. institutional entrepreneurship). However, despite the analytical gains that both of them have brought to the study of institutional change, they are still strongly tied to the assumptions of the research traditions through which they have emerged. A rapprochement between such theoretical schemes allows greater rigor to investigate processes of institutional change and enables greater awareness of the assumptions inherent to each perspective, as well as it encourages the search for more balanced alternatives for explaining institutional maintenance and change. At the heart of this proposal, there is a search for understanding the dynamics of institutional life. The institutional context exhibits a certain level of institutional plasticity and it can be modified according to the availability of practices, meanings, and resources. Therealization of this potential for change is dependent on institutional actors' reflexivity levels, and their munificence of resources. The practices of institutional creation, maintenance, and disruption in a particular context will, therefore, result from the interaction between the institutional context characteristics (the level of institutional plasticity) and the types of institutional actors (the level of institutional discretion) involved.
\end{abstract}

Keywords: Institutional work. Gradual institutional change. Agency. Reflexivity. Institutional context.

\title{
Introdução
}

No presente ensaio teórico busca-se promover uma conciliação entre as abordagens do institutional work (LAWRENCE e SUDDABY, 2006) e da mudança institucional gradual (MAHONEY e THELEN, 2010) e sua articulação em esquema analítico adequado para o avanço da compreensão da dinâmica da mudança institucional. Visa-se, aqui, à identificação de elementos de interface e possíveis sinergias entre essas perspectivas dedicadas à compreensão da dinâmica da manutenção e da mudança institucional.

A abordagem institucional predominante nos estudos organizacionais possui como foco principal o relacionamento entre organizações e campo organizacional, privilegiando o estudo da influência e do controle das instituições sociais sobre as práticas organizacionais e o funcionamento das organizações. Reconhecendo a parcialidade dessa explicação, o trabalho de DiMaggio (1988) buscou reinserir a noção de agência na explicação da mudança institucional. Por meio da elaboração do conceito de empreendedor institucional, o autor forneceu explicação adequada para a criação de novas instituições.

Neste mesmo período, outras explicações concorrentes e complementares emergiram com o intuito de especificar a relação entre agência e instituições. Entre as perspectivas mais conhecidas além daquela do empreendedorismo institucional (GREENWOOD e SUDDABY, 2006; HARDY e MAGUIRE, 2008; KOENE, 2006; LAWRENCE e PHILLIPS, 2004; LECA e NACACHE, 2006; SMOTHERS, MURPHY, NOVICEVIC et al., 2014), é possível citar a abordagem das práticas sociais (BOURDIEU, 1996; GIDDENS, 2003; SCHATZKI, 2006; SCHATZKI, KNORR-CETINA e VON SAVIGNY, 2001) e das habilidades sociais (FLIGSTEIN, 1997; 2001; 2008).

O institutional work é uma entre várias outras vertentes que buscam clarificar o papel da agência na dinâmica institucional. Mohr e White (2008, p. 485, tradução livre) também apresentaram vários exemplos de estudos que tratam as instituições como "[...] mecanismos de articulação que ligam os níveis sociais - conectam sistemas de interação social do nível micro aos níveis meso e macro das organizações; a realidade simbólica com a material e o nível da ação com o estrutural". Entre os exemplos citados pelos autores, aparecem os trabalhos em que se utilizam técnicas de modelagem relacional (network tools) como os de Bearman e Stovel (2000); McLean (1998), Smith (2007) e Sonnet (2004), cujas análises recaem sobre sistemas culturais 
subjacentes a processos institucionais mais amplos; de Breiger e Mohr (2004), Mische (2007) e Tilly (1997) indicando os mapas estruturais que conectam formas culturais com ações institucionais; e de White (1981; 2002), com o mapeamento das bases institucionais dos mercados, indústrias e campos organizacionais.

Estas abordagens ampliam o debate e mostram que há outras formas de se explicar como as instituições são criadas, mantidas e até mesmo interrompidas. De acordo com Greenwood, Oliver, Suddaby et al. (2008), no período de 1991 a 2007, houve um maior reconhecimento da teoria institucional como uma das principais abordagens da teoria das organizações, ocorrendo uma expansão da agenda de aplicações, uma maior sistematização de ideias e a proposição de novos conceitos. Ainda, segundo estes autores (2008, p. 14, tradução livre):

[...] houve um foco em mostrar o isomorfismo e sua dinâmica. Mas, em meados da década [de 1990], a atenção voltou-se para o exame da legitimidade, normalmente acompanhada por uma abordagem mais centrada na agência. Uma linha adicional de pesquisa examinou a mudança institucional, muitas vezes com uma abordagem também focada na agência (como indicado pela adoção do 'empreendedorismo institucional' como um termo [...] central).

Uma proposta de integração dessas abordagens surge com a criação da perspectiva do institutional work. Nesta abordagem propõe-se a abertura de nova vertente de análise, tomando como foco primordial a compreensão da maneira como a ação influencia as estruturas sociais e institucionais. Assim, tem-se como objetivo compreender o trabalho desenvolvido por indivíduos, grupos e organizações no sentido de promover a criação, manutenção e dirupção de instituições (LAWRENCE, SUDDABY e LECA, 2009a).

Em essência, a proposta do institutional work compreende quadro analítico abrangente desenvolvido com o objetivo de conectar e aglutinar, por meio de esquema teórico singular, diversos estudos previamente realizados em uma abordagem integradora. $\mathrm{O}$ institutional work emerge associado à noção de estruturação de práticas sociais e coloca no centro da análise institucional a compreensão da reflexividade e conduta estratégica dos atores sociais como dependente das habilidades por eles exibidas em contextos sociais. Frente à limitação da explicação do empreendedorismo institucional aos processos de criação institucional, o institutional work se abre à explicação dos processos associados de desinstitucionalização e reinstitucionalização (LAWRENCE e SUDDABY, 2006; LAWRENCE, LECA e ZILBER, 2013; LAWRENCE, SUDDABY e LECA, 2009a). A expansão da noção de empreendedorismo institucional engloba ainda a transformação da noção de imersão social de estado em processo, a qual pressupõe que no qual o contexto institucional em que os atores estão imersos é construído com base em suas próprias microações. Assim, "[...] o institutional work amplia o conceito de empreendedorismo institucional na imersão social equivalente a um processo de microconstrução do contexto de imersão social institucional" (JACOMETTI, 2013, p. 71).

Central à proposta apregoada pela vertente de estudo do institutional work é a inversão no interesse das pesquisas que relacionam organizações e instituições. Em lugar de se concentrar nos processos por meio dos quais a ação é influenciada pelas instituições, nessa vertente defende-se a necessidade de se compreenderem as maneiras pelas quais as ações de determinados atores interessados criam, mantêm e diruem instituições. Esses três grandes blocos de análise do institutional work permitem que os pesquisadores concentrem-se tanto no estudo das ações envolvidas na criação de novas instituições, quanto nas práticas destinadas a manter vigentes as instituições ou, ainda, nas atividades de certos atores destinadas a diruir as instituições existentes. Assim, a visão do institutional work congrega e relaciona os esforços desenvolvidos anteriormente, bem como fomenta a realização de estudos futuros com base em estrutura de análise compreensiva (LAWRENCE e SUDDABY, 2006).

Apesar de seu potencial de contribuição, o institutional work continua bastante focado na dimensão da agência e no envolvimento dos atores sociais em processos de mudança institucional. Dessa forma, o artigo 
se inicia com uma breve descrição de como essa abordagem evoluiu na literatura, sendo um conceito preponderante para ajudar a explicar a mudança gradual ou radical, bem como a manutenção do status quo institucional vigente, reconhecendo a existência de relações de influência mútua entre atores e instituições.

Em seguida, são apresentados os fundamentos da mudança institucional gradual, que reforçam a noção de que o papel dos agentes de mudança e seus comportamentos combinam-se com as características do contexto político e institucional de modo a desencadear mudanças. O esquema de análise da mudança institucional gradual está associado à visão do neoinstitucionalismo, e aponta que a compreensão das possibilidades de ação dos atores está diretamente relacionada às características das instituições e do contexto político nos quais eles se encontram imersos.

Ao longo do texto, a conciliação entre as duas visões é iniciada, percebendo-se a possibilidade de se estabelecerem pontes profícuas entre elas. Para atingir o objetivo, um modelo de análise é apresentado juntamente com algumas proposições teóricas. As conclusões alcançadas neste estudo são apresentadas juntamente com as possibilidades teóricas e propostas de estudos futuros.

\section{A Abordagem do Institutional Work}

A abordagem do institutional work é inaugurada com o trabalho de Lawrence e Suddaby (2006). Os autores revisaram quinze anos de pesquisas empíricas publicadas em três dos principais periódicos da área e identificaram conjuntos distintos de institutional work desenvolvido pelos atores, quais sejam: com o objetivo de criar, manter ou diruir instituições. Os autores constataram que as práticas de criação institucional constituem o grupo mais bem documentado na literatura, enquanto ainda são poucos os registros que demonstram o trabalho realizado pelos atores para manter ou diruir instituições. Em cada uma daquelas três grandes categorias, as formas de institutional work foram relacionadas aos elementos que proporcionam suporte institucional, derivados dos trabalhos de DiMaggio e Powell (1983) e Scott (2008), podendo tratar-se de práticas voltadas aos aspectos cognitivos, normativos e regulativos das instituições.

O avanço da perspectiva do institutional work está baseado na reformulação do conceito com vistas a distinguir a noção de esforço institucional do conceito similar e normalmente mais amplo de ação. Central à ideia de institutional work, Lawrence, Suddaby e Leca (2009b) compreendem a existência de conexão entre esforço e resultado. Assim, o institutional work envolveria diferentes tipos e níveis variados de esforços físicos e mentais efetuados pelos atores com o objetivo de provocar certos efeitos em determinada instituição ou conjunto de instituições. Necessário destacar que a conexão entre os esforços realizados e os resultados esperados não é aleatória, mas, como os próprios autores não se furtam em lembrar, existem sempre enquanto práticas socialmente imersas, desenvolvidas com base em orientações institucionais.

A principal noção de esforço associada ao institutional work refere-se ao trabalho de convencimento que denota 'esforço cognitivo' para o reconhecimento de padrões de pensamento e comportamento institucionalizados em rotinas como meio de ampliação dos níveis de reflexividade e controle da (re)produção social (LAWRENCE, LECA e ZILBER, 2013; LAWRENCE, SUDDABY e LECA, 2011). A reflexividade envolve o reconhecimento dos aspectos institucionais incorporados em práticas e rotinas e por meio delas reproduzidos cotidianamente, e sua 'desnaturalização' ou relativização a determinado contexto espaço temporal pelos atores sociais. Esse processo, que pode ser chamado de 'emersão' ou 'desenraizamento institucional' - por referência a movimento contrário ao de imersão social (GRANOVETTER, 1985) -, envolve o reconhecimento dos mecanismos de funcionamento e reprodução de práticas institucionalizadas, ou 'circuito de reprodução' (GIDDENS, 2003). O aumento nos níveis de reflexividade dos atores por referência a outros contextos temporais ou espaciais torná-los-ia mais aptos a desenvolver ações voltadas à criação, manutenção ou dirupção institucional, na medida em que ampliaria os níveis de 'monitoração reflexiva da conduta' e a capacidade de eles se engajarem em processos de 'autorregulação reflexiva'. 
Seguindo as recomendações sobre o desenvolvimento de teorias adequadas para explicar a natureza dinâmica e processual das organizações, Lawrence, Suddaby e Leca (2009b) diferenciam a visão do institutional work entre verbo e substantivo. Destacam que, embora ambos os focos sejam de interesse, a análise do esforço institucional enquanto verbo sugere área mais ampla de investigação, que engloba questões relativas ao 'porquê', 'como', 'quando' e 'onde' os atores trabalham. Defendem que, em vez de ser compreendido como processo linear de criação, manutenção e dirupção institucional, o institutional work deveria ser compreendido por meio de abordagem de práticas sociais (BOURDIEU, 1996; GIDDENS, 2003; SCHATZKI, KNORR-CETINA e VON SAVIGNY, 2001). Dessa maneira, estabelecem como premissas básicas que: os atores individuais e coletivos possuem variados níveis de consciência e reflexividade, assim como diferentes capacidades de atuação social ou habilidades sociais (FLIGSTEIN, 1997); as instituições são sempre, em maior ou menor medida, produto das ações daqueles atores, estejam eles conscientes e interessados nisso ou não; e as ações realizadas pelos atores existem sempre enquanto práticas socialmente imersas (POLANYI, 1944; GRANOVETTER, 1985), desenvolvidas com base em orientações institucionais (LAWRENCE e SUDDABY, 2006) que podem ser mais tácitas ou taken-for-granted ou mais explícitas e formalizadas (BERGER e LUCKMANN, 1996; POLANYI, 1944).

Ao adotar a abordagem de práticas sociais, Lawrence, Suddaby e Leca (2009b) defendem que o dualismo no tratamento da questão da agência precisa ser superado em benefício da visão relacional do fenômeno e estabelecem duas possibilidades para que isso seja feito. Uma primeira frente 'centrada no trabalho' (workcentric), a considera o estudo do institutional work por meio dos efeitos potenciais que por ele podem ser gerados, baseando-se na intencionalidade dos atores para definir o que constitui o institutional work. De acordo com essa visão, ainda que os atores possam gerar outros efeitos distintos daqueles por eles intencionados para a criação, manutenção ou dirupção de instituições, não poderiam ser considerados institutional work. A outra frente de trabalho, 'centrada nas instituições' (institution-centric), está mais alinhada com a visão dos estudos institucionais, estabelecendo as fronteiras da análise do institutional work por meio dos efeitos gerados pelos atores, independentemente das intenções por eles manifestadas, mas destacando a importância dos microprocessos, dos relacionamentos e da ação.

Mesmo considerando a diferença entre as duas abordagens e independentemente de qual seja a orientação dos pesquisadores, em ambos os casos não se pode prescindir de compreensão acurada do contexto institucional no qual os atores encontram-se imersos para o entendimento adequado do institutional work envolvido nos processos de criação, manutenção ou dirupção institucional (KAGHAN e LOUNSBURY, 2011). No caso da primeira abordagem, Lawrence, Suddaby e Leca (2009b) ressalvam a necessidade de se estudar a conexão das motivações dos atores com as características institucionais dos campos organizacionais nos quais eles estão imersos. Em se tratando da versão 'centrada nas instituições', essa questão se torna ainda mais patente, visto que a explicação seja deslocada das motivações para os elementos institucionais na forma de influências sobre as ações ou resultados de suas realizações.

Uma das principais avenidas abertas pelo trabalho de Lawrence e Suddaby (2006) envolve a análise dos atores responsáveis pela realização dos trabalhos institucionais de criação, manutenção e dirupção institucional. Em sua obra, os autores consideram que existem determinadas categorias de atores mais apropriados, ou aptos, para desenvolver determinados tipos de institutional work. No caso da dirupção institucional, por exemplo, consideram que o desenvolvimento de práticas que existem fora dos limites normativos de determinada instituição demandariam atores com alta competência cultural e compreensão acurada das fronteiras e significados institucionais. Já a dirupção institucional por meio do trabalho cognitivo de enfraquecimento de pressupostos e crenças legítimos requereria atores capazes de atuar de maneira original e contra a corrente, em vez de atores poderosos ou culturalmente sofisticados.

Em parte da literatura tende-se a considerar que o envolvimento de certos atores no institutional work necessário para diruir determinado complexo institucional seja geralmente decorrente do fato de os seus interesses não serem adequadamente satisfeitos pelas estruturas existentes (FLIGSTEIN, 2008; LAWRENCE e SUDDABY, 2006). No entanto, acredita-se que seja possível ampliar essa compreensão na medida em que 
a dirupção de certas instituições seja realizada com o intuito de preservar ou fortalecer determinada constelação institucional. A maior parte dos registros acerca dos processos de dirupção institucional consta em estudos sobre a criação de novas instituições por empreendedores institucionais. O que parece não se tratar de mera coincidência, mas indicar que, em muitos casos, existe certa associação entre as formas de institutional work e a possibilidade de reforço mútuo em vez de oposição entre elas.

Apesar da importância dessa questão para o avanço dos estudos sobre o institutional work, ainda são escassos os trabalhos desenvolvidos nessa perspectiva que se dispuseram a elaborar estrutura teórica capaz de discriminar as condições sob as quais se desenvolvem as várias modalidades de institutional work (LAWRENCE, LECA e ZILBER, 2013). A literatura sugere a existência de relação próxima entre certos tipos de ambiente ou contextos institucionais e determinadas categorias de atores envolvidos em atividades de institutional work, mas ainda carece de um modelo abrangente capaz de sintetizar estudos anteriores e delimitar proposições para verificação por futuras pesquisas (FLIGSTEIN, 2001; LAWRENCE e SUDDABY, 2006; SUDDABY e VIALE, 2011). Um dos desafios que se coloca para o avanço das pesquisas sobre institutional work consiste, portanto, na investigação da existência de associações e regularidades entre diferentes categorias de atores, contextos institucionais de atuação e formas de institutional work.

Uma promissora classificação relacionando tipos de contexto, atores e mudança institucional foi desenvolvida por Mahoney e Thelen (2010) com o propósito de avançar na compreensão mais acurada da mudança institucional gradual e pode ser usada para complementar o quadro de análise do institutional work. A proposta dos atores está assentada sobre construção tipológica que relaciona conjuntos de regras institucionais a características do contexto político e institucional como forma de estabelecer a relação entre categorias de atores e formas de mudança e persistência institucional. O estabelecimento de pontos de contato entre as abordagens da mudança gradual e do institutional work possibilita, por um lado, flexibilizar o argumento estruturalista de Mahoney e Thelen (2010) em relação à emergência de categorias de atores dever-se às configurações ambientais e, por outro, apropriar para a abordagem do institutional work fatores de variação contextual que influenciam no estabelecimento das categorias de atores e nas formas de institutional work passíveis de serem desenvolvidas em determinado contexto.

\section{A Abordagem da Mudança Gradual}

Apesar do crescente interesse por explicações institucionais em diversos círculos de pesquisa sobre organizações, existe certo consenso de que ainda faltam instrumentos úteis para explicar a evolução gradual das instituições (ARTHUR, 1994; CLEMENS e COOK, 1999; COLLIER e COLLIER, 1991; MAHONEY, 2000; NORTH, 1990; PIERSON, 2004; THELEN, 1999, 2004). Este é o ponto de partida de Mahoney e Thelen (2010) para buscar uma explicação mais adequada sobre os processos de mudança institucional e, em especial, de mudança institucional gradual.

Evitando incorrer nas dificuldades encontradas pelas abordagens anteriores de análise institucional, Mahoney e Thelen (2010) adotam a abordagem de poder distribuído, comum às pesquisas do institucionalismo histórico e presentes em algumas vertentes do institucionalismo sociológico e da escolha racional. Mas em vez de partir deste ponto para questões de conformidade ou resistência dos atores, incorporam nova dimensão relativa às possibilidades de interpretação e aplicação das regras institucionais de novas maneiras. A mudança institucional ocorre frequentemente quando os problemas de interpretação e aplicação da regra abrem espaço para os atores implementarem as regras existentes de novas maneiras (LAWRENCE e SUDDABY, 2006; MAHONEY e THELEN, 2010; WHITTINGTON, 1992).

O modelo de mudança institucional gradual desenvolvido por Mahoney e Thelen (2010) resgata pressupostos de trabalhos clássicos como o de Merton (1970) sobre a prescrição de estruturas sociais e culturais e anomia; de March e Olsen (1984) sobre os fatores organizacionais na vida política; e de Oliver (1991) sobre respostas 
estratégicas para a formação de processos institucionais. Os autores apresentam um conjunto de proposições que relaciona modos particulares de mudança a determinadas características do contexto institucional e às propriedades das instituições que possibilitam ou influenciam a emergência de certos agentes de mudança e formas de transformação institucional. Segundo o pressuposto básico adotado pelos autores, as instituições são instrumentos de distribuição de poder (HALL e TAYLOR, 1996; MAHONEY e THELEN, 2010; SKOCPOL, 1995). De acordo com essa abordagem, as instituições estão repletas de tensões que levantam questionamentos inevitáveis sobre recursos. Em alguns casos, o poder de um grupo ou coalizão em relação a outro torna-se tão grande que os atores dominantes são capazes de projetar instituições que correspondem às suas preferências institucionais.

As instituições existem sempre incorporadas em normas tácitas ou suposições que estão muitas vezes implícitas entre os atores. Tal entendimento compartilhado pode existir em graus diferentes e pode mudar com o tempo, sendo também capaz de desencadear mudanças institucionais; muito embora as regras formais possam permanecer inalteradas. $\mathrm{Na}$ ausência de tais entendimentos institucionais compartilhados, 'predadores' podem minar sistematicamente as regras como forma de violar este entendimento comum. O que torna importante reconhecer que a estabilidade institucional depende não somente da continuidade das regras em si, mas também das maneiras pelas quais essas regras são constituídas e aplicadas na prática (STREECK e THELEN, 2005).

Desta forma, o contexto político é entendido como o conjunto de atores que atuam e se relacionam num determinado campo organizacional e que por algum motivo detêm poder e são capazes de implementar ações para promover mudanças institucionais (CARPENTER, 2001; LIEBERMAN, 2006; MAHONEY e THELEN, 2005). O contexto institucional refere-se ao conjunto dos elementos ambientais de natureza institucional e técnica que envolve as organizações e com o qual elas interagem (SCOTT, 2008). Pode apresentar-se em três níveis: local/regional, nacional e internacional. Estes três níveis podem ser compreendidos por meio da noção de contexto institucional de referência de uma organização (MACHADODA-SILVA e FONSECA, 1996; MACHADO-DA-SILVA, FONSECA e FERNANDES, 2000). As características dos contextos político e institucional definem os parâmetros limítrofes dos tipos de mudança institucional que se podem esperar em determinados contextos.

Com base em Streeck e Thelen (2005), Mahoney e Thelen (2010) delinearam cinco tipos de mudança institucional: (1) deslocamento: remoção das regras existentes e introdução de novas regras; (2) em camadas: sobreposição de regras ou adição de novas às existentes; (3) derivação/desvio: mudança de regras como resultado de mudanças no ambiente; (4) conversão: mudança das regras existentes como forma de readaptação estratégica; (5) exaustão: processo de ruptura e extinção institucional. As instituições podem, com o tempo, deixar de fazer sentido em virtude do que ocorre ao seu redor, isto é, mudanças bruscas econômicas ou políticas. A adequada compreensão dos tipos possíveis de mudança institucional e do papel desempenhado por apoiadores e desafiadores serve de base para a análise das situações empíricas de transformação política e institucional.

Os contextos político e institucional provocam efeitos que moldam o tipo de agente de mudança dominante que tende a emergir e florescer. Os tipos de ação deste agente podem desencadear a mudança. Por sua vez, os tipos de atores e as ações mais adequadas para a realização das mudanças ou manutenção do status quo também variam de acordo com as diferenças contextuais. A questão chave é como conceituar as dimensões das instituições e do contexto político que mais importam para explicar variações na forma de mudança institucional. Assim, seria possível contemplar as ações que os diferentes tipos de agentes são mais susceptíveis de conduzir para desencadear a mudança em diversos contextos institucionais, bem como especificar quem são os agentes por trás dessas mudanças. Disso deriva que a mudança institucional pode ser também subproduto não intencional das lutas distribuídas de uma multiplicidade de atores. $\mathrm{O}$ caráter de regras institucionais existentes e do contexto político prevalecente são os principais fatores explicativos para a emergência de diferentes agentes de mudança. 
O Quadro 1 apresenta as categorias de agentes que podem surgir para conduzir as mudanças em diferentes contextos. Mahoney e Thelen (2010) dimensionaram quatro tipos básicos de agente de mudança: insurgentes, simbiontes (parasitas ou mutualistas), subversivos e oportunistas. Os agentes são definidos com base em duas questões elementares: (I) Os atores possuem interesse em preservar as regras institucionais existentes? (II) Os atores respeitam as regras institucionais vigentes? No modelo dos autores, qualquer ator pode, em diferentes contextos e situações, desenvolver papéis distintos no contexto da política institucional. Como exemplo, determinado ator adota postura oportunista em determinado campo ou arena institucional ou assume o papel de insurgente em outro contexto ou em outro período no tempo.

Além disso, não é necessário que determinado conjunto de atores esteja sempre associado com a responsabilidade pelas transformações. Os autores enfatizam que a mudança institucional pode ser subproduto não intencional, desenvolvido em virtude de lutas distribuídas entre os atores ou de sua associação. Considera-se que o sucesso de vários tipos de agentes para efetuar mudanças dependa das coalizões que eles são capazes de forjar. Embora essas coalizões sejam influenciadas pelo ambiente específico, acredita-se que seja possível fazer generalizações sobre diferentes situações nas quais certos atores serão ou não capazes de estabelecer alianças com outros que se beneficiam da manutenção ou alteração das regras vigentes.

\section{Quadro 1}

\section{Combinação entre contexto político e instituições para a formação de agentes de mudança e tipos de mudança ${ }^{5}$}

\begin{tabular}{|c|c|c|c|}
\hline & & \multicolumn{2}{|c|}{ Características das Instituições } \\
\hline & & $\begin{array}{l}\text { Baixo Nível de Poder } \\
\text { Discricionário na } \\
\text { Interpretação/Imposição }\end{array}$ & $\begin{array}{l}\text { Alto Nível de Poder } \\
\text { Discricionário na } \\
\text { Interpretação/Imposição }\end{array}$ \\
\hline \multirow{2}{*}{$\begin{array}{l}\text { Características do } \\
\text { Contexto Político }\end{array}$} & $\begin{array}{l}\text { Fortes } \\
\text { Possibilidades } \\
\text { de Veto }\end{array}$ & $\begin{array}{l}\text { Subversivos } \\
\text { (Sobreposição) }\end{array}$ & $\begin{array}{l}\text { Simbiontes } \\
\text { (Derivação/Desvio) }\end{array}$ \\
\hline & $\begin{array}{l}\text { Fracas } \\
\text { Possibilidades } \\
\text { de Veto }\end{array}$ & $\begin{array}{l}\text { Insurgentes } \\
\text { (Deslocamento) }\end{array}$ & $\begin{array}{l}\text { Oportunistas } \\
\text { (Conversão) }\end{array}$ \\
\hline
\end{tabular}

Fonte: adaptado de Mahoney e Thelen (2010, p. 19).

Os quatro tipos de agentes que podem surgir no contexto político e as respectivas mudanças com as quais eles estão associados são apresentados a seguir.

1. Os insurgentes, quando prevalecem em conflitos, podem provocar uma rápida inversão do status quo institucional em favor de regras radicalmente novas. Insurgentes, portanto, seriam especialmente ligados a padrões de deslocamento total. O deslocamento rápido das instituições é justamente o seu objetivo. Se a mudança ocorrer de forma gradual, é porque os insurgentes são incapazes de fazer as coisas mudarem tão rapidamente quanto eles gostariam.

\footnotetext{
${ }^{5}$ A exaustão institucional não foi incluída no Quadro 1, enquanto tipo de mudança, devido à ausência de características tanto do contexto político como das instituições.
} 
2. Há duas variedades de agentes simbiontes, os parasitas e os mutualistas. Ambos os casos dependem e são capazes de prosperar em instituições de criação diversa de sua própria. Os parasitas exploram uma instituição para ganhos privados, mesmo quando a instituição é benéfica para o alcance de seus objetivos. Apesar de dependerem da instituição, algumas ações desenvolvidas pelos parasitas contradizem o 'espírito' ou finalidade da instituição e geram pequenas fraturas que podem alargar-se com o passar do tempo e promover mudança em deriva. Já os mutualistas também prosperam e se beneficiam das regras estabelecidas e são capazes de utilizá-las estrategicamente para promover os seus interesses. Sua diferença em relação aos parasitas é que as ações que desenvolvem não comprometem a eficiência das regras ou a sobrevivência institucional. Ainda que possam violar as regras estabelecidas, os mutualistas o fazem com o intuito de apoiá-las e sustentá-las em sua essência. Mutualistas são essenciais para reforçar instituições vigentes, pois ampliam o apoio da coalizão na qual a instituição repousa. No entanto, podem também associar-se, em algumas situações, a atores oportunistas com o intuito de promover mudança em conversão.

3. O terceiro grupo de atores são os subversivos. Buscam substituir uma instituição existente, mas em geral não violam as regras institucionais vigentes em busca de seus objetivos. Aparentemente podem até ser adeptos das instituições, mas com o tempo avançam rumo a uma postura de oposição e desafio. Enquanto aguardam por alterações, podem incentivar mudanças institucionais por meio da proliferação de novas regras e práticas. Ao disseminar novos modelos em paralelo a práticas existentes, desviam o apoio ao regime anterior e contribuem para a emergência de novos padrões institucionais. Desse modo, os subversivos em particular estariam associados com processos de sedimentação institucional ou com padrões de mudança institucional que se desenvolvem em sobreposição de camadas. Nessa modalidade, novos elementos institucionais são enxertados ou adicionados a padrões antigos sem substituí-los ou eliminá-los imediatamente. No entanto, dependendo das características do contexto políticoinstitucional, podem incentivar a conversão completa ao novo modelo institucional.

4. O grupo de oportunistas engloba atores com preferências ambíguas sobre a continuidade institucional. Embora não objetivem preservar as instituições vigentes, ações de oposição ao status quo implicam dispêndio de tempo e recursos. Assim, em geral, não contrariam diretamente o sistema institucional vigente. Ao contrário, este conjunto de atores procura explorar as possibilidades existentes no próprio sistema vigente como meio para a consecução dos seus objetivos. Desse modo, os oportunistas tornar-se-iam importante fonte de inércia institucional. Preferem explorar possibilidades existentes a arriscar-se em promover mobilização para a mudança. Isso os torna bons aliados dos atores que pretendem manter uma instituição existente. Além de identificar as assimetrias de poder, são capazes de explicar por que mudar um status quo institucional é geralmente muito mais difícil do que defendê-lo. Apesar disso, quando ocupam posição de agentes de mudança, os oportunistas envolvem-se em ações que promovem ambiguidades na interpretação ou aplicação de regras e anteveem o espaço para reimplantar estas regras de forma inesperada.

Em resumo, Mahoney e Thelen (2010) buscam generalizar sobre a afinidade entre determinados tipos de atores e modos de mudança da seguinte forma: insurgentes procuram deslocamento rápido, mas se contentam com o deslocamento gradual. Eles podem aparecer em qualquer ambiente, mas são mais propensos a florescer em ambientes caracterizados por fracas possibilidades de veto. Possibilidades de veto se referem à 
capacidade que um determinado ator social tem de inibir e/ou anular o efeito das ações de outros atores no campo. Enforcement ${ }^{6}$ baixo é bastante compatível com ações de deslocamento imediato (ao contrário de conversão ou de desvio), enquanto menor possibilidade de veto significa que os defensores do status quo deterão posição significativa para resistir e combater os esforços dos insurgentes.

Os simbiontes procuram preservar o status quo institucional formal, mas a sua variedade parasitária realiza ações que causam desvio institucional. Sua emergência está relacionada a ambientes caracterizados por fortes possibilidades de veto e de enforcement elevado. Eles desejam manter o status quo institucional, e os atores com alta capacidade de veto ajudam a garantir isso. Ao mesmo tempo, no entanto, simbiontes parasitas têm necessidade de cumprimento das regras, pois isso lhes garante a criação de espaço para alterar a valência e o significado de regras institucionalizadas. Valência, aqui, diz respeito à tendência do que deve ser feito pelos atores imersos num campo organizacional, como se fosse uma carga de atração para o que é dado como certo.

Os subversivos procuram o deslocamento de trabalho no curto prazo mediante a realização de mudanças em camadas ou por meio de sedimentação institucional (COOPER, HININGS, GREENWOOD et al.,1996). Pode-se esperar que subversivos surjam e prosperem em contextos com possibilidades de veto forte e interpretação/cumprimento das regras baixo. Isto torna difícil para os atores de oposição romper as regras de uma instituição. Neste ambiente, os agentes de mudança devem trabalhar dentro do sistema para atingir seus objetivos.

Os oportunistas adotam uma postura de cautela e espera para analisar a situação e perseguir a conversão quando convém aos seus interesses. Tendem a prosperar em ambientes onde há elevada apreciação na forma como as instituições são promulgadas e há pouca possibilidade de veto.

Neste cenário, os apoiadores podem ser indulgentes com aqueles que voluntariamente convertem instituições para seus próprios fins, desde que não se oponham totalmente às regras institucionais. Além disso, desafiadores não precisam buscar ações insurgentes entre as lacunas das regras institucionalizadas. Em vez de se oporem a instituições definitivas, captam recursos, agindo como oportunistas para reimplantar regras vigentes segundo seus propósitos.

O sucesso dos vários agentes na realização de mudanças não depende unicamente da sua capacidade individual de mobilizar recursos, mas está também associado às coalizões que eles são capazes de forjar com outros atores. Dessa maneira, seu poder relativo é importante na medida em que afeta sua capacidade de organizar a coalizão de interesses que necessitam ou para promover a mudança dos acordos existentes ou resistir a eles. Embora essas coalizões sejam influenciadas pelo ambiente situacional em cada caso específico, é possível fazer generalizações sobre como diferentes atores podem ou não fazer alianças com aqueles que se beneficiam ou não das regras vigentes.

Com base na exposição precedente, considera-se que a proposta teórica elaborada por Mahoney e Thelen (2010) oferece categorias analíticas importantes e complementares ao quadro teórico produzido pela abordagem do institutional work.

Lawrence e Suddaby (2006) indicam que boa parte dos estudos em teoria institucional focou na mudança, pela possibilidade de perceber mais claramente os elementos de análise, e que, no entanto, interessa também compreender os processos de manutenção e dirupção de instituições.

${ }^{6} \mathrm{O}$ conceito de enforcement refere-se à capacidade de se fazer cumprir uma lei, uma regra, um contrato, e não possui uma correspondência direta com outro conceito da Língua Portuguesa. 
Ainda que neste trabalho o interesse maior permaneça sobre a explicação da mudança institucional, acreditase que a conciliação das abordagens do institutional work e da mudança gradual seja interessante em todas as fases do ciclo de vida institucional. Desse modo, agrega dimensão de previsão ou expectativa teórica na medida em que oferece ferramentas para se analisar em quais casos a mudança é mais ou menos propícia e quando as formas de institutional work são mais efetivas em promover transformações no arranjo institucional existente ou em atuar segundo sua manutenção ou dirupção.

\section{Conciliação entre Institutional Work e Mudança Institucional Gradual}

A conciliação dos elementos da abordagem do institutional work e da teoria da mudança gradual permite equalizar as dimensões da agência e da estrutura e, com isso, oferecer explicação mais adequada da dinâmica da mudança institucional com base no engajamento dos atores em práticas de criação, manutenção ou dirupção institucional.

Apesar de ambas as correntes de análise estarem baseadas em diferentes visões acerca da definição de instituição, salienta-se que estas não são incompatíveis e podem ser facilmente conciliadas na medida em que, em ambos os casos, o núcleo do conceito está diretamente relacionado à dimensão do poder, fundamentalmente associado à questão da agência e da mudança institucional. O Quadro 2 sintetiza as relações identificadas entre as duas correntes de análise.

A perspectiva da mudança institucional gradual atribui grande centralidade às questões de poder, interesses e distribuição de recursos. Em verdade, instituições são definidas como "[...] instrumentos distribucionais carregados de implicações de poder" (MAHONEY e THELEN, 2010, p. 8) e, quando compreendidas em relação às características de determinado contexto político, estabelecem categorias de atores e possibilidades de mudança institucional. Nessa abordagem são, portanto, os elementos estruturais do contexto político e de uma instituição focal que contêm neles mesmos as possibilidades de mudança.

Já a abordagem do institutional work tem seu fundamento na tradição do neoinstitucionalismo de vertente sociológica e decorre de uma tentativa de prover uma estrutura analítica para agrupar as pesquisas institucionalistas focadas na compreensão das ações desenvolvidas por certos atores sociais com o propósito de criar, manter ou diruir instituições (LAWRENCE e SUDDABY, 2006).

Ao buscar desenvolver explicação mais completa e dinâmica para a mudança institucional do que propunham os adeptos da vertente do empreendedorismo institucional (BATTILANA, LECA e BOXENBAUM, 2009; DIMAGGIO, 1988), no entanto, os autores reiteram o foco nos atores e sua agência, definindo as categorias de institutional work com base em seus interesses e ação propositada.

Dessa descrição depreende-se que, embora com ambas as abordagens tenha-se pretendido oferecer uma análise mais dinâmica e balanceada para a mudança institucional, elas não se desprendem da tradição mais estruturalista e 'agencialista' nas quais estão embasadas. A explicação para a mudança institucional permanece uma faculdade das estruturas institucionais segundo a abordagem da mudança gradual e um resultado do engajamento de atores em formas de institutional work de acordo com a outra abordagem. A possibilidade de se desenvolver proposta alternativa e mais equilibrada de explicação da dinâmica institucional de permanência e transformação surge com a conciliação das principais contribuições de cada uma das perspectivas em nova abordagem integradora. Essa possibilidade reside no reconhecimento da importância de ambas as dimensões, do ator e do contexto, da agência e da estrutura, na promoção da explicação da dinâmica institucional. 


\section{Quadro 2}

Diferenças, semelhanças e pontos de convergência entre as abordagens do institutional work e da mudança institucional gradual

\begin{tabular}{|c|c|c|}
\hline & \multicolumn{2}{|c|}{ Concepções Teóricas } \\
\hline & Institutional Work & Mudança Institucional Gradual \\
\hline \multirow{4}{*}{ Diferenças } & $\begin{array}{l}\text { Centrada nos atores sociais e suas } \\
\text { práticas }\end{array}$ & $\begin{array}{l}\text { Centrada nos contextos e oportunidades para } \\
\text { a ação }\end{array}$ \\
\hline & $\begin{array}{l}\text { Ênfase na criação, manutenção e } \\
\text { dirupção institucional }\end{array}$ & $\begin{array}{l}\text { Ênfase nos processos de mudança institucional } \\
\text { gradual }\end{array}$ \\
\hline & $\begin{array}{l}\text { A mudança institucional é explicada por } \\
\text { meio das ações de empreendedores } \\
\text { institucionais que superam as forças de } \\
\text { manutenção institucional }\end{array}$ & $\begin{array}{l}\text { A mudança institucional é explicada por meio } \\
\text { da interação entre interesses dos atores e } \\
\text { oportunidades de ação existentes no contexto }\end{array}$ \\
\hline & $\begin{array}{l}\text { Classifica os atores sociais de acordo com } \\
\text { o nível de imersão social em que se } \\
\text { encontram e os associa aos tipos de } \\
\text { institutional work }\end{array}$ & $\begin{array}{l}\text { Classifica os atores com base nos interesses } \\
\text { manifestos de acordo com características do } \\
\text { contexto político e das instituições sociais }\end{array}$ \\
\hline \multirow{2}{*}{ Semelhanças } & $\begin{array}{l}\text { O contexto institucional é importante } \\
\text { para situar os atores sociais nas suas } \\
\text { possibilidades de ação no campo }\end{array}$ & $\begin{array}{l}\text { O contexto institucional associado ao político } \\
\text { influencia os tipos de atores sociais que } \\
\text { podem surgir no campo }\end{array}$ \\
\hline & $\begin{array}{l}\text { Envolve análise do trabalho desenvolvido } \\
\text { pelos atores sociais, sua imersão em } \\
\text { contextos institucionais, com foco em } \\
\text { processos de mudança, manutenção e } \\
\text { dirupção institucional }\end{array}$ & $\begin{array}{l}\text { Envolve análise dos tipos de atores sociais, sua } \\
\text { emergência em posições definidas em } \\
\text { diferentes contextos institucionais e políticos, } \\
\text { com foco em processos de mudança, } \\
\text { sedimentação, ajuste e exaustão institucional }\end{array}$ \\
\hline \multirow{3}{*}{$\begin{array}{l}\text { Pontos de } \\
\text { Convergência }\end{array}$} & \multicolumn{2}{|c|}{$\begin{array}{l}\text { As abordagens são complementares, pois enquanto a perspectiva do institutional work se } \\
\text { baseia nos atores e suas práticas para compreender os processos de mudança e } \\
\text { manutenção das estruturas institucionais, a abordagem da mudança gradual se vale das } \\
\text { características das instituições e do contexto político para definir as categorias de atores e } \\
\text { possibilidades de mudança institucional }\end{array}$} \\
\hline & \multicolumn{2}{|c|}{$\begin{array}{l}\text { As características das instituições com as quais os atores se defrontam e o contexto político } \\
\text { no qual estão inseridos estabelecem limites estruturais para a explicação baseada no } \\
\text { institutional work, do mesmo modo que as características dos atores, suas necessidades e } \\
\text { interesses definem fronteiras explicativas para a proposta da abordagem da mudança } \\
\text { gradual }\end{array}$} \\
\hline & \multicolumn{2}{|c|}{$\begin{array}{l}\text { A perspectiva da mudança institucional gradual amplia a compreensão acerca do } \\
\text { envolvimento simultâneo dos atores em diversas formas de institutional work, assim como } \\
\text { permite separar ações de caráter imediato de ações cujos efeitos serão sentidos no longo } \\
\text { prazo }\end{array}$} \\
\hline
\end{tabular}




\begin{abstract}
A tipologia de atores e formas de mudanças prevista na abordagem da mudança institucional gradual pode ser relacionada com os tipos de institutional work desenvolvido pelos atores em um dado campo organizacional

As categorias de atores centrais e periféricos definidas pelo institutional work podem ser refinadas a partir da tipologia de atores definida pela abordagem da mudança institucional gradual
\end{abstract}

Fonte: elaborado pelos autores.

O desenvolvimento de quadro teórico compreensivo que abarca e relaciona características de ambas as abordagens assenta-se sobre alguns pressupostos cujo fundamento principal está na noção de dualidade da estrutura (GIDDENS, 2003). Este conceito esclarece que a prática social pressupõe agência como capacidade e estrutura como possibilidade, e que a realização de determinada prática ou seu enactment (re)produz ambas as dimensões da agência e estrutura no tempo e no espaço. Dessa maneira, para a explicação da permanência ou mudança de instituições é preciso considerar tanto as estruturas existentes em determinado contexto institucional como a capacidade de ação e formas de agência em que os atores são capazes de se engajar. A compreensão das práticas sociais e da dinâmica de mudança e manutenção institucional deixa de ser um resultado previsto e pré-determinado teoricamente e demanda verificação empírica da lógica de estruturação de determinada atividade (ROSSONI, GUARIDO FILHO e CORAIOLA, 2013). O entendimento da recursividade entre agência e estrutura sustenta, portanto, a aproximação das propostas do institutional work e da mudança institucional gradual.

A associação entre as abordagens da mudança gradual e do institutional work sinaliza que a manutenção e a mudança institucional não podem ser vistas de maneira estanque e funcional, mas compreendem processos dinâmicos de estruturação. A perspectiva do institutional work destaca que apesar de as principais definições do conceito de instituição enfatizarem seu caráter de permanência e fixidez, é preciso reconhecer que a base de reprodução dessas instituições está alicerçada nas ações de atores individuais e coletivos (BERGER e LUCKMANN, 1996; GIDDENS, 2003). Já a abordagem distributiva da mudança gradual lembra que estes atores não se defrontam com contextos externos à sua própria atividade, mas que é a própria interação com outros atores que define os contornos do contexto na medida em que as ações daqueles atores podem fornecer novos significados e interpretações, bem como constituir elementos de veto ou reforço às atividades de determinado ator focal.

Dessa forma, os atores sociais não estão envolvidos em um único tipo de institutional work, mas se associam e colaboram direta e indiretamente para o desenvolvimento de múltiplas formas de institutional work, que podem ser sincrônicas ou diacrônicas. Esse entendimento considera a existência de uma multiplicidade de atores envolvidos simultaneamente e também sequencialmente no tempo em diversos tipos de institutional work, cujas práticas podem produzir algum tipo de reforço mútuo ou mesmo contradizer e conflitar entre si, gerando consequências para a manutenção ou mudança das instituições no tempo e no espaço. Isso permite também separar o propósito do engajamento dos atores em práticas de criação, manutenção e dirupção institucional do resultado de suas ações. A perspectiva do institutional work apresenta relação linear direta entre o propósito intencionado pelos atores e o resultado da sua ação, mas estudos recentes têm demonstrado que não há uma correspondência exata entre os tipos de institutional work em que se engajam os atores e o propósito de manutenção ou mudança institucional intencionado - ex.: McGaughey (2013).

Ao se definir uma estrutura analítica derivada de pesquisas empíricas com o objetivo de apresentar mapeamento das formas de institutional work identificadas na literatura, faz-se necessário tomar cuidado para que ela não seja adotada prima facie por futuros autores como modelo que associa respectivas intenções a formas de trabalho. $\mathrm{O}$ envolvimento dos atores nas formas de institutional work associado à criação de novas instituições ou dirupção de instituições existentes pode ter como objetivo fortalecer instituições 
previamente existentes e garantir a manutenção do arranjo institucional vigente com sua estrutura de distribuição de posições e recursos. De outro modo, quando se considera que a emergência de determinadas instituições pode ser facilitada pela permanência ou dirupção de outras instituições, o institutional work de manutenção ou dirupção institucional pode ser visto como elemento recursivo do processo de criação institucional. Também o desenvolvimento de novas instituições, ou mesmo a manutenção de certos complexos institucionais em vez de outros, podem atuar como elementos que contribuem para que certas instituições sejam diruídas em lugar de outras. A consequência dos múltiplos engajamentos dos atores em formas de criação, manutenção e dirupção institucional será, portanto, resultado dinâmico da interação entre os atores em determinado contexto institucional e, assim, permanece dependente do escrutínio empírico dos pesquisadores.

\section{Esquema Analítico e Proposições Teóricas}

A tipologia de atores desenvolvida por Mahoney e Thelen (2010) pode ser produtivamente associada ao quadro teórico do institutional work. O reconhecimento da importância das características das instituições com as quais os atores se defrontam e do contexto político no qual estão inseridos apresenta importantes possibilidades para a construção de explicações sistemáticas acerca do institutional work a ser desenvolvido por determinados tipos de atores. No entanto, o foco exclusivo nas questões estruturais retira da dimensão da agência qualquer poder explicativo para o engajamento dos atores com práticas capazes de gerar a manutenção ou a mudança das estruturas institucionais. A proposta de conciliação desenvolvida neste artigo reintroduz essa dimensão e busca equalizar a participação de elementos do contexto e dos atores na explicação dos tipos de institutional work. A conexão entre atores, contextos e institutional work está representada na Figura 1.

O esquema da Figura 1 considera que o engajamento dos atores em diferentes formas de institutional work seja dependente de dois conjuntos de fatores associados a um contexto específico (Plasticidade Institucional) e a um ator em particular (Discricionariedade Institucional). A noção de Plasticidade Institucional é definida genericamente como a capacidade de determinada instituição em ser alterada, ou o potencial de alteração de determinado arranjo institucional. Essa potencialidade é definida de acordo com o nível de munificência ambiental e ambiguidade institucional. 
Figura 1

Relação entre Atores, Contextos e Institutional Work

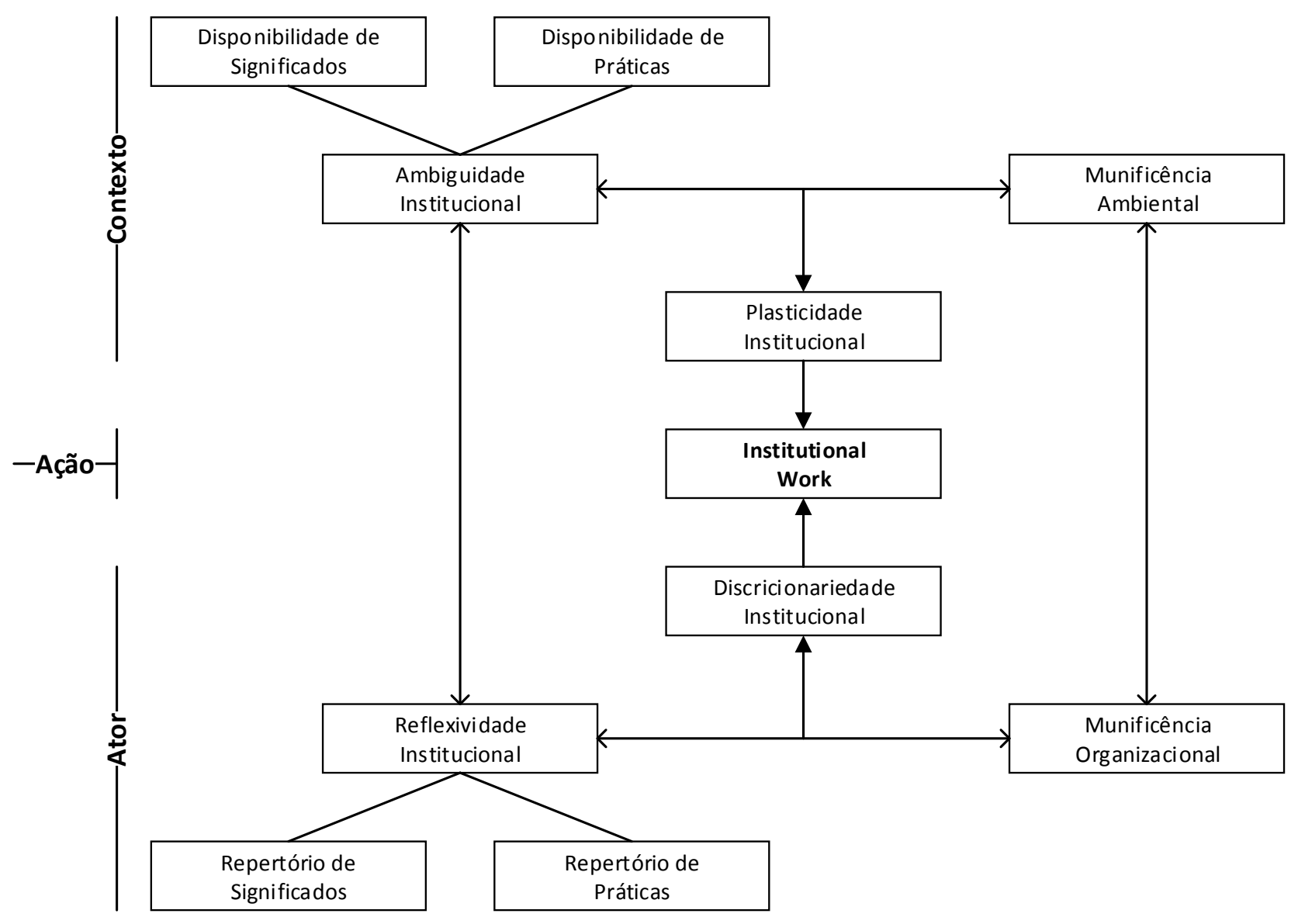

Fonte: elaborado pelos autores.

Por munificência ambiental, entende-se a "[...] escassez ou abundância de recursos críticos necessários por (uma ou mais) firmas que operam em um contexto" (CASTROGIOVANNI, 1991, p. 542). Pressupõe-se que os níveis de munificência ambiental e os níveis de ambiguidade institucional estejam diretamente relacionados, mas ainda se faz necessário investigar os detalhes desta relação empiricamente. Ainda que se acredite que um nível de ambiguidade elevado tenda a gerar menor certeza quanto à criticidade dos recursos e maior abundância relativa de recursos, aponta-se que nos contextos de ambiguidade extrema, os atores podem envolver-se na criação de mitos e rituais legitimadores como mecanismos de segurança ontológica para minimizar a ambiguidade e aumentar a certeza quanto à criticidade dos recursos ${ }^{7}$. Também são necessárias novas pesquisas para avaliar se quanto mais abundantes os recursos disponíveis no ambiente, maiores as possibilidades de combinação e uso de recursos e, por conseguinte, maiores tendem a ser a variedade e disponibilidade potencial de práticas e significados, elementos que definem a noção de ambiguidade institucional.

\footnotetext{
${ }^{7}$ Agradecemos a um dos revisores ocultos por destacar esse ponto.
} 
À capacidade de uma organização focal engajar-se em alguma forma de trabalho institucional em um contexto espaço temporalmente definido chamou-se discricionariedade institucional. $\mathrm{O}$ termo discretion, originalmente, trata da liberdade de decisão em determinada situação sem considerar, necessariamente, os limites que se impõem a esta liberdade - e neste caso se distingue do conceito mais usual de poder discricionário utilizado no Direito brasileiro, que limita a liberdade aos ditames legais. Muito embora não haja uma correspondência exata para a tradução deste termo, optou-se pela manutenção desta terminologia por três razões: 1) mesmo na concepção mais restrita do termo, existem limites à capacidade de ação organizacional definidos pela estrutura e manifestos na noção de plasticidade institucional; 2) mantém-se a terminologia original de Mahoney e Thelen (2010) quando refletem sobre a capacidade de as organizações escolherem diferentes interpretações e aplicações das regras institucionais, ainda que ampliada com a dimensão da munificência organizacional; e 3) o conceito de discricionariedade institucional remete a outro conceito correlato amplamente disseminado na área de estudos organizacionais que é a noção de discricionariedade administrativa, ou managerial discretion no original de Hambrick e Finkelstein (1987).

A discricionariedade institucional de uma organização é resultado da dinâmica entre os níveis de reflexividade institucional e munificência organizacional. O primeiro desses fatores compreende a capacidade dos atores em reconhecer as condições de reprodução do sistema institucional e identificar alternativas de interpretação e ação. Assim, a capacidade reflexiva da organização é função do repertório de práticas e significados que ela possui e está diretamente associada ao nível de ambiguidade institucional e da disponibilidade de recursos ou munificência organizacional. Por um lado, quanto maiores os níveis de reflexividade de uma organização, menor a percepção da ambiguidade ambiental, isto é, menos ela tende a se defrontar com o ambiente como uma realidade externa e opressora, fora de seu alcance e ininteligível. Por outro lado, quanto maiores os níveis de reflexividade organizacional (ex.: advindos de experiências anteriores, adquiridas com parceiros), maior tende a ser também a munificência organizacional, na medida em que um repertório maior de práticas e significados possibilita o acesso e a ativação de um conjunto maior de recursos organizacionais. Por sua vez, a munificência organizacional é codependente da disponibilidade de recursos no ambiente e influi diretamente na capacidade reflexiva da organização, ensejando o desenvolvimento e enactment de novas práticas e significados.

A possibilidade de uma organização focal engajar-se em algum tipo de trabalho institucional existe como resultado da reflexividade dos atores e da disponibilidade de alternativas existentes no contexto, e ambas as dimensões estão recursivamente associadas. A noção de contexto compreende tanto contextos reais quanto imaginários, que podem existir no passado, presente ou futuro e que são evocados e instanciados por meio da interação com determinado ator ou conjunto de atores (BÁTIZ-LAZO, HAIGH e STEARNS, 2014; KODEIH e GREENWOOD, 2014). A disponibilidade de práticas refere-se, então, aos níveis de conhecimento e acesso dos atores a ações passíveis de serem desenvolvidas tanto no sentido de promover o reforço das estruturas existentes quanto visando realizar qualquer tipo de mudança. Por fim, ainda que possuam poder discricionário suficiente, a efetivação da ação permanecerá latente a menos que o contexto ofereça oportunidades para a realização da ação. A ideia de possibilidades de ação oferecidas pelo contexto envolve o reconhecimento de que, mesmo no caso de os atores serem capazes de identificar circuitos de reprodução institucional e estarem cônscios da existência de práticas capazes de contribuir para a manutenção ou modificação dos arranjos institucionais, faz-se necessário que possuam capacidade de mobilizar recursos e de se envolver em práticas políticas e culturais para minimizar o poder de veto de outros atores e tornar possível a efetivação de suas intenções. Com base nessas considerações, são possíveis as proposições a seguir.

Proposição 1: o engajamento de um ator em institutional work de criação, manutenção ou diruição institucional é resultado da relação entre os níveis de plasticidade institucional do contexto e a capacidade de discricionariedade institucional do ator.

A literatura documenta os processos de importação de práticas e significados de outros campos organizacionais como um dos principais mecanismos para a geração de mudanças institucionais 
(LEBLEBICI et al., 1991). Esse processo de contato e comparação entre contextos organizacionais distintos encontra-se diretamente relacionado à capacidade discricionária dos atores e remete à esfera cultural da dimensão cultural-cognitiva definida por Scott (2008), por meio da qual os agentes ampliam os níveis de racionalização da sua própria conduta e seu conhecimento acerca dos circuitos de reprodução institucional (GIDDENS, 2003). O fato de boa parte dos trabalhos que analisaram a introdução de novas práticas por meio da vertente do empreendedorismo institucional terem atribuído sua emergência à influência de práticas provenientes de outros campos organizacionais corrobora essa interpretação (MAGUIRE, HARDY e LAWRENCE, 2004). A mudança institucional nestes casos emergiria da interseção entre dois ou mais campos (SUDDABY e GREENWOOD, 2005), ou da própria periferia do campo em análise (LEBLEBICI et al., 1991). A análise do relacionamento entre práticas e fronteiras em campos organizacionais realizada por Zietsma e Lawrence (2010) generaliza os resultados desses estudos e aponta para a existência de três tipos de institutional work relacionados à delimitação dos campos organizacionais: o trabalho de fechamento (closure), de conexão (connection) com outros campos e de ampliação do escopo (breaching) ou amplitude do campo.

Além da diferença entre elementos materiais e simbólicos das práticas oriundas de campos distintos, há de se considerar também as situações de sobreposição e as fronteiras entre diferentes lógicas institucionais, fontes importantes na teorização sobre a mudança institucional. Na visão de Greenwood, Raynard, Kodeih et al. (2011), a ideia de reflexividade pode ser entendida como a habilidade de a organização comparar diferentes lógicas institucionais e, em virtude disso, minimizar o caráter imperativo que normalmente reveste as pressões e demandas exercidas sobre as empresas. Desta feita, organizações que se posicionam nas margens ou nos interstícios de múltiplas lógicas institucionais (SEO e CREED, 2002) tenderiam a se defrontar com maior complexidade institucional e maior nível de contradições institucionais. Estas contradições, por um lado, corresponderiam a maiores demandas sobre a organização e, por outro, em nível ampliado de reflexividade que poderia contribuir para minimizar as pressões institucionais ou tornar mais flexíveis as respostas estratégicas da organização (KODEIH e GREENWOOD, 2014). De acordo com a afirmação de Greenwood e Suddaby (2006, p. 38, tradução livre): “[...] uma posição na rede que interconecta campos [e podemos adicionar: que transpõe diferentes lógicas] reduz a imersão institucional por meio da exposição dos atores a incompatibilidades interinstitucionais, ampliando a consciência deles quanto a alternativas".

Proposição 1.1: atores posicionados nas fronteiras de um campo organizacional tendem a apresentar maiores níveis de reflexividade institucional e possuem acesso a gama mais variada de recursos do que atores mais imersos no campo organizacional.

Na medida em que os atores se tornam menos imersos em seus contextos institucionais, ou possuem outros referentes institucionais - sejam eles reais ou imaginários e façam referência a situações no passado, presente ou futuro (EMIRBAYER e MISCHE, 1998) - com base nos quais possam identificar-se, efetuar comparações ou basear sua conduta -, deve ocorrer aumento na capacidade reflexiva da organização quanto às influências institucionais sobre suas ações e, por decorrência, maior capacidade de desenvolvimento de ações intencionadas à criação, manutenção ou dirupção institucional (GREENWOOD, RAYNARD, KODEIH et al., 2011; KODEIH e GREENWOOD, 2014). Tal fenômeno é identificado também por autores que adotam a noção de contexto institucional de referência (MACHADO-DA-SILVA e FONSECA, 1996). Já os laços fracos estabelecidos pelos atores - como amplamente demonstrado pelas pesquisas sobre redes sociais - promovem a diversidade e a difusão de padrões e significados em determinada rede (GRANOVETTER, 1973), e os atores que ocupam buracos estruturais na rede possuem maior acesso a recursos e informações do que atores que ocupam posições mais centrais (BURT, 1992). A ampla disponibilidade de práticas e significados em contexto caracterizado por frouxas amarras institucionais e por grande abundância de recursos constitui condição favorável à criação de novas instituições.

Proposição 2: atores com alta discricionariedade institucional inseridos em contextos com alta plasticidade institucional tendem a engajar-se em atividades visando à criação de novas instituições. 
Essa situação é bastante característica de mercados em formação (SANTOS e EISENHARDT, 2009), contextos de 'corrida do ouro' (LEFSRUD e SUDDABY, 2012) e bolhas econômicas (GARBER, 2001), em que o amplo espaço de interpretação e ambiguidade institucional associado à larga disponibilidade de recursos favorece a discricionariedade institucional dos atores. Em campos organizacionais caracterizados por altos níveis de plasticidade institucional, com estruturas sociais fluidas, grande variedade de significados e ampla variedade e disponibilidade de recursos, os atores competem fortemente tanto pelo acesso a recursos quanto pelo domínio na definição de práticas e significados, delimitando as fronteiras do campo e as posições dos atores dentro dele (GAWER e PHILLIPS, 2013; SANTOS e EISENHARDT, 2009). O caso da criação da indústria do king crab ilustra bem essa dinâmica (ALVAREZ, YOUNG e WOOLLEY, 2014). As ações desenvolvidas por Lowell Wakefield e sua equipe redundaram no surgimento de uma nova atividade econômica, com padrões de exploração econômica, tecnologia própria e regulamentações governamentais. Em um contexto com poucas amarras institucionais, incerteza tecnológica e poucos atores envolvidos, a atuação interessada de um empreendedor focado exclusivamente no lucro pode originar a emergência de um novo mercado e uma série de instituições a ele associadas.

Outra situação emerge nos casos em que o contexto institucional existente, embora altamente plástico do ponto de vista dos demais atores que participam do campo, não seja favorável às atividades de determinado ator focal. Nestes casos, os atores que se encontram em condição desfavorável podem buscar engajar-se em práticas que visam ampliar sua capacidade reflexiva e seus níveis de munificência organizacional e que, por conseguinte, proporcionem melhor posição relativa aos demais atores participantes do campo. Neste caso, muito embora esses atores possam buscar desenvolver ações visando à criação de novas instituições mais benéficas ao ator em foco, considera-se que a possibilidade de engajar-se na construção dessas instituições surja somente com a eliminação ou modificação das instituições vigentes no campo e seja, portanto, secundária ao envolvimento dos atores com formas de institutional work voltadas à dirupção institucional. Disso decorre a proposição a seguir.

Proposição 3: atores com baixa discricionariedade institucional inseridos em contextos com alta plasticidade institucional tendem a engajar-se em atividades visando à dirupção de instituições existentes.

Em geral, quando o contexto político envolve grandes possibilidades de veto, a mudança tende a ser produzida por meio da alteração nos significados e interpretações associados a determinado conjunto de regras institucionais e na diversificação nas formas de aplicá-las (MAHONEY e THELEN, 2010). A literatura mostra como os atores que detêm baixa capacidade discricionária em face a um contexto ocupado por atores com alta capacidade reflexiva e acesso a recursos buscam solapar as fontes de recursos da elite institucional e convertê-las em fontes de recursos próprios. O trabalho de Smothers, Murphy, Novicevic et al. (2014) sinaliza que, por meio da ação coletiva e de alianças estratégicas, empreendedores institucionais conseguem superar a resistência à substituição de políticas institucionais desiguais, enquanto estabelecem novas práticas e normas.

Novamente isso fica mais claro no caso de campos emergentes, que proporcionam várias oportunidades para que atores que detêm pouco poder possam mobilizar os recursos que possuem e, coletiva ou individualmente, envolver-se na dirupção de instituições existentes e na elaboração de outros arranjos institucionais mais favoráveis às suas capacidades e recursos (MAGUIRE, HARDY e LAWRENCE, 2004). Conforme demonstrado pelo trabalho de Rojas (2010), indivíduos e grupos podem envolver-se na reconfiguração de instituições existentes com o propósito de ampliar a legitimidade de suas posições e seu acesso a recursos, criando uma plataforma para adquirir ainda mais poder no campo e realizar seus projetos e interesses.

Caso diferente ocorre em contextos de baixa plasticidade institucional. Nestas situações, atores que possuem altos níveis de discricionariedade institucional buscarão manter sua vantagem com relação aos demais atores. Por sua vez, atores com baixos níveis de capacidade discricionária encontrarão poucas oportunidades no contexto para efetivar qualquer tipo de mudança e, em geral, tenderão também a envolver-se em formas de manutenção institucional. A maior diferença consiste no fato de que, no primeiro caso, os altos níveis de 
reflexividade institucional aliados a um contexto de baixa plasticidade institucional oferecem aos atores mais reflexivos a vantagem de articular os padrões de significado e práticas no campo de maneira a manter suas posições de poder. Já no caso de atores com pouca capacidade discricionária, a tendência é a repetição pouco reflexiva dos padrões vigentes no campo, não raro reproduzindo e disseminando práticas e significados produzidos e respaldados por atores mais centrais e com maior poder discricionário. Essas ideias estão sintetizadas nas proposições 4 e 5 a seguir.

Proposição 4: atores com alta discricionariedade institucional inseridos em contextos com baixa plasticidade institucional tendem a engajar-se em atividades visando à manutenção das instituições existentes.

Campos organizacionais maduros são aqueles em que existem baixos níveis de ambiguidade com relação a práticas e significados e os recursos disponíveis no ambiente já estão distribuídos, em geral, desigualmente entre os atores. Nestes contextos, os atores que dispõem de maior repertório de práticas e significados e também maior acesso a recursos ocupam posições mais centrais e tendem a trabalhar para preservar suas posições na estrutura do campo organizacional. A principal orientação destes atores visa à manutenção das estruturas institucionais existentes, uma vez que são benéficas a eles enquanto membros de uma elite institucional. A manutenção institucional é processo dinâmico (EMIRBAYER e MISCHE, 1998) e está baseada no envolvimento de um ou mais atores com formas de institutional work de manutenção. Dessa maneira, complementarmente às formas listadas por Lawrence e Suddaby (2006), considera-se que certos processos de criação institucional e dirupção institucional possam também ser usados com o propósito de manter o status quo institucional. O caso das cinco maiores companhias multinacionais de auditoria desenvolvido por Greenwood e Suddaby (2006) ilustra claramente a questão da criação institucional. Outra pesquisa exemplifica o institutional work de defesa, em que podem engajar-se atores centrais a determinado campo organizacional com o propósito de buscar defender-se de pressões para mudança exercidas por atores externos ao campo em questão. Conforme demonstram Maguire e Hardy (2009), os atores usualmente buscam repelir as pressões externas para mudança. Nos casos em que isso não é possível, buscam traduzir as pressões externas, mesmo havendo certa perda para a capacidade institucional da organização. A situação é bastante diferente nos casos em que os atores possuem baixa capacidade reflexiva e poucos recursos.

Proposição 5: atores com baixa discricionariedade institucional inseridos em contextos com baixa plasticidade institucional tendem a engajar-se em atividades visando à manutenção de instituições existentes.

Nos casos em que atores com poucos recursos e repertório pequeno de práticas e significados estão imersos em campos organizacionais com baixa ambiguidade institucional e recursos concentrados nas mãos de outros atores, a tendência é que o impacto de suas ações para a esfera institucional seja limitado à reprodução das estruturas existentes. Neste caso, o engajamento dos atores em práticas de institutional work em geral é fruto de pouca reflexão e escolha e se pauta na maior parte das vezes pela repetição de padrões e fórmulas aprendidas no passado. Elementos como tradição, rotinas e scripts geralmente regem a atuação destes atores nestes contextos, quase sempre associados a processos isomórficos de difusão e repetição de padrões institucionalizados (DIMAGGIO e POWELL, 1983). Um caso emblemático da literatura que demonstra a importância dos rituais organizacionais para a manutenção institucional é apresentado por Dacin, Munir e Tracey (2010). Os autores realizaram pesquisa na universidade de Cambridge e descrevem elegantemente as formas como o engajamento dos alunos com o conjunto de rotinas do jantar formal oferecido pela universidade contribuem para a manutenção de importantes instituições sociais, como a divisão de classes sociais na Inglaterra.

Para detalhar melhor as possíveis interações entre níveis de plasticidade e discricionariedade institucional, vale destacar ainda o comportamento dos atores que possuem níveis médios de capacidade reflexiva e acesso a recursos. O caso desses atores é distinto dos anteriores, visto que sua posição é pela manutenção institucional tanto nos casos de alta plasticidade quanto baixa plasticidade institucional. Assim como atores 
com alta discricionariedade institucional trabalharão para manter e reproduzir suas posições, atores com níveis médios de discricionariedade buscarão proteger suas posições para não perder vantagens vis-à-vis outros atores no campo. Diferente de atores que possuem baixo poder discricionário, atores que apresentam discricionariedade institucional mediana irão também buscar a manutenção de suas vantagens em um contexto de escassez material e simbólica. Disso decorre a proposição a seguir.

Proposição 6: atores com médios níveis de discricionariedade institucional tendem a engajar-se em atividades de manutenção institucional, independente dos níveis de plasticidade institucional.

Um exemplo do que se está chamando de atores com níveis médios de discricionariedade pode ser identificado no que Wright e Zammuto (2013) definiram como grupos de médio status. Esses atores estão alocados entre atores com maior e menor capacidade discricionária e medeiam os processos de mudança por eles iniciados. Em geral, estes atores estão envolvidos com atividades de manutenção institucional e se envolverão com processos de mudança na medida em que percebam neles alguma vantagem ou benefício em termos de ampliação dos níveis de reflexividade ou acesso a recursos (MAHONEY e THELEN, 2010). Outra razão para que eles se engajem em processos de mudança institucional é quando percebem algum tipo de ameaça à própria sobrevivência do grupo ou à manutenção dos valores e propósitos do campo organizacional. Nestes casos, poderão aliar-se a grupos que pretendem tanto a criação quanto a dirupção institucional. Isso sugere que não são somente atores com baixo poder discricionário que irão engajar-se na criação de redes e alianças para mobilização da ação coletiva (SMOTHERS, MURPHY, NOVICEVIC et al., 2014), mas que essa pode ser uma estratégia também usada por outros atores do campo. A essas considerações, seguem-se as proposições 6.1 e 6.2 ,

Proposição 6.1: atores com níveis intermediários de discricionariedade institucional estão mais propensos a se engajar em atividades de criação institucional quando associados com outros atores de capacidade discricionária similar ou quando cooptados por atores com alta discricionariedade institucional.

Proposição 6.2: atores com níveis intermediários de discricionariedade institucional estão mais propensos a se engajar em atividades de dirupção institucional quando associados com outros atores de capacidade discricionária similar ou quando cooptados por atores com baixa discricionariedade institucional.

Similar aos casos em que os atores possuem alta discricionariedade em ambiente de alta plasticidade institucional, em que a tendência de constituição de instituições ocorre por meio de processos de sedimentação institucional (COOPER, HININGS, GREENWOOD et al., 1996; TOLBERT e ZUCKER, 1996), pressupõe-se que as mudanças graduais nas instituições tendam a ocorrer mais frequentemente se mais balanceadas forem as forças dos atores em determinado contexto institucional, ou maior for a participação de atores com níveis médios de discricionariedade institucional (MAHONEY e THELEN, 2010). Nestas situações, existe grande possibilidade de os atores se engajarem primeiramente em projetos voltados à construção de sua capacidade reflexiva e base de recursos para só posteriormente decidirem se envolver em atividades mais profundas de transformação institucional. Ou seja, o engajamento dos atores em formas de institutional work promoveria mobilidade social no campo, a qual por sua vez possibilitaria o desenvolvimento de outros tipos de institutional work (WALDRON, FISHER e NAVIS, 2014).

O apelo à abordagem de Mahoney e Thelen (2010) possibilita também ampliar a compreensão acerca do envolvimento simultâneo dos atores em diversas formas de projeto e de institutional work (SUDDABY e VIALE, 2011), assim como separar ações de caráter imediato daquelas de longo prazo. Conforme informam algumas pesquisas realizadas sobre institutional work (GAWER e PHILLIPS, 2013; LAWRENCE, SUDDABY e LECA, 2009a; SUDDABY e VIALE, 2011), as atividades voltadas à criação, manutenção e dirupção de instituições são realizadas por uma variedade de atores, dentre os quais os mais importantes tendem a ser o Estado e as associações profissionais. Acredita-se, desse modo, que ambos os conjuntos de atores estarão normalmente envolvidos no desenvolvimento de mais de uma forma de institutional work. Além disso, em certas situações poderão interessar-se por criar novas instituições e, em outras, desenvolver 
esforços visando mantê-las e também por vezes trabalhar para diruir certas estruturas. Disso decorre que as práticas de criação, manutenção e dirupção institucional precisam ser vistas como de ocorrência simultânea (ZIETSMA e LAWRENCE, 2010), a cargo de diferentes atores ou resultantes do envolvimento múltiplo de certos atores em projetos distintos e compreendendo a possibilidade de contradições e complementaridades entre si (LAWRENCE, SUDDABY e LECA, 2011).

Além do envolvimento simultâneo com distintas instituições e projetos institucionais, faz-se necessário considerar também que os atores podem não exibir atitude clara com relação aos seus interesses e intenções em relação a determinados complexos institucionais e, mais do que isso, podem manifestar expectativas ambíguas com relação ao desenvolvimento ou continuidade institucional (MAHONEY e THELEN, 2010). É provável que o envolvimento desses atores com determinados tipos de institutional work esteja menos relacionado com os efeitos ou consequências pretendidas como resultado do trabalho desenvolvido e mais fortemente associado a outros fatores correlatos de maior importância para a manutenção de benefícios imediatos associados à posição ou ao status social dos atores.

Essas considerações apontam para a importância de se compreender a noção de institutional work desenvolvido pelos atores como um fluxo de atividades em vez de uma série de esforços descontínuos. Assim, é fundamental a separação entre ações e decisões associadas com a realização de interesses imediatos e de curto prazo do envolvimento em projetos mais amplos e de maior duração inseridos em ações de prazos mais longos de concretização. O reconhecimento dessas diferenças possibilita compreender o fato de certos atores desenvolverem esforços que à primeira vista pareceriam contradizer interesses manifestos e contextualizar essas ocorrências por meio de planos estratégicos mais abrangentes.

\section{Conclusões}

Neste artigo demonstrou-se que existem mais pontos comuns de convergência do que diferenças entre as duas abordagens tratadas - que resgatam e sintetizam os resultados da conversão realizada entre as diferentes concepções teóricas. Ao se propor uma conciliação entre as duas abordagens, contribui-se com um esquema analítico e proposições para estudar as relações entre os diferentes perfis dos atores sociais, contextos institucionais e políticos e formas de institutional work. Não se pretende esgotar as possibilidades de análise, mas, ao contrário, estimular os pesquisadores a se debruçarem sobre esta temática em pesquisas futuras.

A articulação de elementos de ambas as propostas sinaliza para a necessidade de compreensão global do processo e para a busca de equilíbrio na consideração quanto ao potencial de causalidade exercido por elementos estruturais e de ação quando da explicação dos processos de manutenção e mudança institucional. A adoção da perspectiva de práticas sociais fornece caminho adequado à conciliação de aspectos de ambas as propostas, do institutional work e da mudança gradual, para a construção de teorização sobre as principais tendências de associação entre formas de institutional work, características do contexto institucional e tipos de atores sociais.

Com base no exposto, a principal contribuição do artigo para o institucionalismo foi apresentar um modelo teórico de conciliação entre as duas perspectivas aventadas, uma vez que os pesquisadores, ao desenvolverem seus projetos de pesquisa por meio da perspectiva institucional de análise, têm grande dificuldade para lidar com os níveis de análise concomitantemente. Dessa forma, com esta contribuição, é possível delimitar estudos observando a perspectiva do ator e a simultaneidade das influências contextuais e, desse modo, entender como surge a ambiguidade institucional, muitas vezes colocada como limitação de pesquisa. Assim, as contribuições que a perspectiva do institutional work pode receber dessa maior aproximação com os elementos da proposta da mudança gradual relacionam-se à compreensão de como os elementos contextuais, as categorias de atores sociais e os tipos de esforço envolvidos nas formas de institutional work reforçam a realização das intenções desses atores, considerando as possibilidades 
oferecidas pelos elementos do contexto. Por sua vez, a abordagem da mudança gradual pode beneficiar-se da introdução da perspectiva do institutional work na medida em que possibilita a flexibilização do pressuposto segundo o qual os atores emergem de acordo com o contexto institucional no qual estão inseridos. Em decorrência disso, favorece-se a emergência de visão mais proativa quanto à possibilidade de aquela parcela de atores desenvolver institutional work de forma isolada ou em associação a outros atores interessados, visando à transformação daquele mesmo ambiente institucional para beneficiá-los em situações futuras.

Como sugestão para estudos futuros é possível indicar a realização de trabalhos que busquem efetuar verificação empírica das categorias e relacionamentos apresentados no presente ensaio. Uma importante consideração é que o modelo não é estático, mas incorpora a possibilidade de mudanças dinâmicas e recursivas entre os níveis de plasticidade e reflexividade institucional. Atores podem tornar-se mais reflexivos ou ampliar seus níveis de acesso a recursos, e, na medida em que isso ocorre, modificam-se as condições ambientais para os demais atores do campo. Também são bem-vindos estudos dedicados a elaborar em maiores detalhes e aprofundar os construtos e seu relacionamento, assim como o modelo analítico esboçado. Considera-se, aqui, temática rica e importante a dinâmica entre formas de institutional work, contextos institucionais e categorias de atores sociais. Esta temática não só demanda maior exploração teórico-empírica como pode trazer várias contribuições para o entendimento da dinâmica da mudança institucional.

\section{Referências}

ALVAREZ, S. A.; YOUNG, S. L.; WOOLLEY, J. L. Opportunities and institutions: a co-creation story of the king crab industry. Journal of Business Venturing, v. 30, n. 1, p. 95-112, 2015. Disponível em: <http://dx.doi.org/10.1016/j.jbusvent.2014.07.011>. Acesso em: 20 out. 2014.

ARTHUR, W. B. Increasing returns and path dependence in the Economy. Ann Arbor: University of Michigan Press, 1994.

BÁTIZ-LAZO, B.; HAIGH, T.; STEARNS, D. L. How the future shaped the past: the case of the cashless society. Enterprise and Society, v. 15, n. 1, p. 103-131, 2014.

BATTILANA, J.; LECA, B.; BOXENBAUM, E. How actors change institutions: towards a theory of institutional entrepreneurship. The Academy of Management Annals, v. 3, n. 1, p. 65-107, 2009.

BEARMAN, P. S.; STOVEL, K. Becoming a Nazi: a model for narrative networks. Poetics, v. 27, p. 69-90, 2000.

BERGER, P. L.; LUCKMANN, T. A construção social da realidade. 27. ed. Rio de Janeiro: Vozes, 1996.

BOURDIEU, P. Razões práticas: sobre a teoria da ação. Campinas: Papirus, 1996.

BREIGER, R. L.; MOHR, J. W. Institutional logics from the aggregation of organizational networks: operational procedures for the analysis of counted data. Computational and Mathematical Organization Theory, v. 10, p. 17-43, 2004.

BURT, S. R. Structural holes: the social structure of competition. Cambridge: Harvard University Press, 1992.

CARPENTER, D. P. The forging of bureaucratic autonomy. Princeton: Princeton University Press, 2001.

CASTROGIOVAnNI, G. J. Environmental munificence: a theoretical assessment. The Academy of Management Review, v. 16, n. 3, p. 542-565, 1991. 
CLEMENS, E. S.; COOK, J. M. Politics and institutionalism: explaining durability and change. Annual Review of Sociology, v. 25, p. 441-466, 1999.

COLLIER, R. B.; COLlIER, D. Shaping the political arena: critical junctures, the labor movement, and regime dynamics in Latin America. Princeton: Princeton University Press, 1991.

COOPER, D. J. et al. Sedimentation and transformation in organizational change: the case of Canadian law firms. Organization Studies, v. 17, n. 4, p. 623-647, 1996.

DACIN, M. T.; MUNIR, K.; TRACEY, P. Formal dining at Cambridge colleges: linking ritual performance and institutional maintenance. Academy of Management Journal, v. 53, p. 1393-1418, 2010.

DIMAGGIO, J. P. Interest and agency in institutional theory. In: ZUCKER, L. G. (Ed.). Institutional patterns and organizations: culture and environment. Cambridge, MA: Ballinger, 1988. 3-22 p.

DIMAGGIO, J. P.; POWELL, W. W. The iron cage revisited: institutional isomorphism and collective rationality in organizational fields. American Sociological Review, v. 48, n. 8, p. 147-160, 1983.

EMIRBAYER, M.; MISCHE, A. What is agency? American Journal of Sociology, v. 103, n. 4, p. 962-999, 1998.

FLIGSTEIN, N. Social skill and institutional theory. American Behavioral Scientist, v. 40, p. 397- 405, 1997.

FLIGSTEIN, N. Social skill and the theory of fields. Sociological Theory, v. 19, n. 2, p. 105-125, 2001.

FLIGSTEIN, N. Fields, power, and social skill: a critical analysis of the new institutionalisms. International Public Management Review, v. 9, n. 1, 2008.

GARBER, P. M. Famous first bubbles: the fundamentals of early manias. Massachusetts, MIT Press, 2001.

GAWER, A.; PHILLIPS, N. Institutional work as logics shift: the case of Intel's transformation to platform leader. Organization Studies, v. 34, n. 8, p. 1035-1071, 2013.

GIDDENS, A. A constituição da sociedade. 2. ed. São Paulo: Martins Fontes, 2003.

GRANOVETTER, M. S. The strength of weak ties. American Journal of Sociology, v. 78, n. 6, p. 1360-1380, 1973.

GRANOVETTER, M. Economic action and social structure: the problem of embeddedness. American Journal of Sociology, v. 91, n. 3, p. 481-510, 1985.

GREENWOOD, R. et al. (Eds.). The Sage handbook of organizational institutionalism. Los Angeles: Sage, 2008.1 $46 \mathrm{p}$.

GREENWOOD, R. et al. Institutional complexity and organizational responses. The Academy of Management Annals, v. 5, n. 1, p. 317-371, 2011.

GREENWOOD, R.; SUDDABY, R. Institutional entrepreneurship in mature fields: the big five accounting firms. Academy of Management Journal, v. 49, n. 1, p. 27-48, 2006.

HALL, P.; TAYLOR, R. C. R. Political science and the three new institutionalisms. Political Studies, v. 44, p. 936$957,1996$.

HAMBRICK, D. C.; FINKELSTEIN, S. Managerial discretion: a bridge between polar views of organizational outcomes. In: STAW, B.M.; CUMMINGS, L. L. (Eds.). Research in Organizational Behavior, Greenwich: JAI Press, 1987.v. 9. 369-406 p. 
HARDY, C.; MAGUIRE, S. Institutional entrepreneurship. In: GREENWOOD, R. et al. (Orgs.). Handbook of organizational institutionalism. London: Sage, 2008. 198-217 p.

JACOMETTI, M. Institutional work na conformação do conhecimento difundido em redes interorganizacionais: estudo de APLs no Estado do Paraná. 402f. Tese (Doutorado em Administração) - Programa de Pós-graduação em Administração da Universidade Federal do Paraná. Curitiba, 2013.

KAGHAN, W.; LOUNSBURY, M. Institutions and work. Journal of Management Inquiry, v. 20, n. 1, p. 73-81, 2011.

KODEIH, F.; GREENWOOD, R. Responding to institutional complexity: the role of identity. Organization Studies, v. 35, n. 1, p. 7-39. 2014.

KOENE, B. A. Situated human agency, institutional entrepreneurship and institutional change. Journal of Organizational Change Management, v. 19, n. 3, p. 365-382, 2006.

LAWRENCE, T. B.; LECA, B.; ZILBER, T. B. Institutional work: current research, new directions and overlooked issues. Organization Studies, v. 34, n. 8, p. 1023-1033, 2013.

LAWRENCE, T. B.; PHILLIPS N. From Moby Dick to Free Willy: macro-cultural discourse and institutional entrepreneurship in emerging institutional fields. Organization, v. 11, p. 689-711, 2004.

LAWRENCE, T. B.; SUDDABY, R. Institutions and institutional work. In: CLEGG, S. et al. (Eds.). The Sage handbook of organization studies. 2. ed. London: Sage, 2006.215-254 p.

LAWRENCE, T. B.; SUDDABY, R.; LECA, B. Institutional work: actors and agency in institutional studies of organizations. Cambridge: Cambridge University Press, 2009a.

LAWRENCE, T. B.; SUDDABY, R.; LECA, B. Introduction: theorizing and studying institutional work. In: LAWRENCE, T. B.; SUDDABY, R.; LECA, B. (Eds.). Institutional work: actors and agency in institutional studies of organizations. Cambridge: Cambridge University Press, 2009b. 1-27 p.

LAWRENCE, T. B.; SUDDABY, R.; LECA, B. Institutional work: refocusing institutional studies of organization. Journal of Management Inquiry, v. 20, n. 1, p. 52-58, 2011.

LEBLEBICI, H. et al. Institutional change and the transformation of interorganizational fields: an organizational history of the U.S. radio broadcasting industry. Administrative Science Quarterly, v. 36, p. 333-363, 1991.

LECA, B.; NACACHE, P. A critical realist approach to institutional entrepreneurship. Organization, v. 13, n. 5, p. 624-651, 2006.

LEFSRUD, L.; SUDDABY, R. After the gold rush: the role of professionals in the emergence and configuration of organizational fields. In: REIHLEN, M.; WERR, A. Handbook of Research on Entrepreneurship in Professional Services. Cheltenham: Edward Elgar, 2012. 318-339 p.

LIEBERMAN, R. Private power and American bureaucracy: the EEOC, civil rights enforcement, and the rise of affirmative action. In: ANNUAL MEETING OF THE AMERICAN POLITICAL SCIENCE ASSOCIATION, 2006, Philadelphia. Proceedings... Philadelphia: August 3, 2006.

MACHADO-DA-SILVA, C. L.; FONSECA, V. S. da. Competitividade organizacional: uma tentativa de reconstrução analítica. Organizações \& Sociedade, v. 4, n. 7, p. 97-114, 1996.

MACHADO-DA-SILVA, C. L.; FONSECA, V. S. da; FERNANDES, B. H. R. Cognição e institucionalização na dinâmica da mudança em organizações. In: CUNHA, M. P.; RODRIGUES, S. B. (Eds.). Estudos organizacionais: novas perspectivas na administração de empresas (uma coletânea Luso-Brasileira). São Paulo: Iglu, 2000. 123-150 p. 
MAGUIRE, S.;HARDY, C. Discourse and deinstitutionalization: the decline of DDT. Academy of Management Journal, v. 52, n. 1, p. 148-178, 2009.

MAGUIRE, S.; HARDY, C.; LAWRENCE, T. B. Institutional entrepreneurship in emerging fields: HIV/AIDS treatment advocacy in Canada. Academy of Management Journal, v. 47, n. 5, p. 657-679, 2004.

MAHONEY, J. Path dependence in historical Sociology. Theory and Society, v. 29, p. 507-548, 2000.

MAHONEY, J.; THELEN, K. A theory of gradual institutional change. In: MAHONEY, J.; THELEN, K. Explaining institutional change: ambiguity, agency, and power. New York: Cambridge University Press, 2010. 1-37 p.

MARCH, J. G.; OLSEN, J. P. The new institutionalism: organizational factors in political life. American Political Science Review, v. 78, p. 734-749, 1984.

MCGAUGHEY, S. L. Institutional entrepreneurship in North American lightning protection standards: rhetorical history and unintended consequences of failure. Business History, v. 55, n. 1, p. 73-97, 2013.

MCLEAN, P. A frame analysis of favor seeking in the Renaissance: agency, networks, and political culture. American Journal of Sociology, v. 104, p. 51-91, 1998.

MERTON, R. K. Estrutura social e anomia. In: MERTON, R. K. Sociologia, teoria e estrutura. São Paulo: Meste Jou, 1970.

MISCHE, A. Partisan publics: contention and mediation across Brazilian youth activist networks. Princeton: Princeton University Press, 2007.

MOHR, J. W.; WHITE, H. C. How to model an institution. Theory and Society, v. 37, p. 485-512, 2008.

NORTH, D. C. Institutions, institutional change, and economic performance. New York: Cambridge University Press, 1990.

OLIVER, C. Strategic responses to institutional process. Academy of Management Review, v. 16, n. 1, p. 145-179, 1991.

PIERSON, P. Politics in time: History, institutions, and social analysis. Princeton: Princeton University Press, 2004.

POLANYI, K. The great transformation. New York: Farrar, 1944.

ROJAS, F. Power through institutional work: acquiring academic authority in the 1968 Third World Strike. Academy of Management Journal, v. 53, n. 6, p. 1263-1280, 2010.

ROSSONI, L.; GUARIDO FILHO, E. R.; CORAIOLA, D. M. Recomendações metodológicas para a adoção da perspectiva da estruturação nos estudos organizacionais. Organizações \& Sociedade, v. 20, n. 66, p. 523-542, 2013.

SANTOS, F. M.; EISENHARDT, K. M. Constructing markets and shaping boundaries: entrepreneurial power in nascent fields. Academy of Management Journal, v. 52, n. 4, p. 643-671, 2009.

SCHATZKI, T. R. On organizations as they happen. Organization Studies, v. 27, n. 12, p. 1863-1873, 2006.

SCHATZKI, T. R.; KNORR-CETINA, K.; Von SAVIGNY, E. The practice turn in contemporary theory. New York: Routledge, 2001.

SCOTT, W. R. Institutions and organizations: ideas and interests. 3. ed. Los Angeles: Sage Publications, 2008.

SEO, M. G.; CREED, W. E. D. Institutional contradictions, praxis, and institutional change: a dialectical perspective. The Academy of Management Review, v. 27, n. 2, p. 222-247, 2002. 
SKOCPOL, T. Why I am an historical institutionalist. Polity, v. 28, p. 103-106, 1995.

SMITH, T. Narrative boundaries and the dynamics of ethnic conflict and conciliation. Poetics, v. 35, p. 22-46, 2007.

SMOTHERS, J. et al. Institutional entrepreneurship as emancipating institutional work: James Meredith and the Integrationist Movement at Ole Miss. Journal of Management History, v. 20, n. 1, p. 114-134, 2014.

SONNETT, J. Musical boundaries: intersections of form and content. Poetics, v. 32, p. 247-264, 2004.

STREECK, W.; THELEN, K. Introduction: institutional change in advanced political economies. In: STREECK, W.; THELEN, K. (Eds.). Beyond continuity: institutional change in advanced political economies. Oxford: Oxford University Press, 2005. 1-39 p.

SUDDABY, R.; GREENWOOD, R. Rhetorical strategies of legitimacy. Administrative Science Quarterly, v. 50, n. 1, p. 35-67, 2005.

SUDDABY, R.; VIALE, T. Professionals and field-level change: institutional work and the professional project. Current Sociology, v. 59, n. 4, p. 423-442, 2011.

THELEN, K. Historical institutionalism in comparative politics. Annual Review of Political Science, v. 2, p. 369-404, 1999.

THELEN, K. How institutions evolve: the Political Economy of skills in Germany, Britain, the United States, and Japan. New York: Cambridge University Press, 2004.

TILLY, C. Parliamentarization of popular contention in Great Britain, 1758-1834. Theory and Society, v. 26, p. 245273, 1997.

TOLBERT, P. S.; ZUCKER, L. G. The institutionalization of institutional theory. In: CLEGG, S.; HARDY, C.; NORD, W. R. (Eds.). Handbook of organization studies. London: Sage, 1996. 169-184 p.

WALDRON, T. L.; FISHER, G.; NAVIS, C. Institutional entrepreneurs' social mobility in organizational fields. Journal of Business Venturing, v. 30, n. 1, p. 131-149, 2015.

WHITE, H. C. Where do markets come from. American Journal of Sociology, v. 87, p. 517-547, 1981.

WHITE, H. C. Markets from networks: socioeconomic models of production. Princeton NJ: Princeton University Press, 2002.

WHITTINGTON, R. Putting Giddens into action. Journal of Management Studies,v. 29, n. 6, p. 693-712, 1992.

WRIGHT, A. L.; ZAMMUTO, R. F. Wielding the willow: processes of institutional change in English county cricket. Academy of Management Journal, v. 56, n. 1, p. 308-330, 2013.

ZIETSMA, C.; LAWRENCE, T. B. Institutional work in the transformation of an organizational field: the interplay of boundary work and practice work. Administrative Science Quarterly, v. 55, n. 2, p. 189-221, 2010. 